\title{
Effect of Some Manfacturing Parameters on Machining of Extruded $\mathrm{Al}-\mathrm{Al}_{2} \mathrm{O}_{3}$ Composites
}

\author{
A. Fathy, M. Abdelhameed, and F. Shehata \\ Department of Mechanical Design and Production Engineering, Faculty of Engineering, Zagazig University, P.O. Box 44519, \\ Zagazig, Egypt \\ Correspondence should be addressed to A. Fathy, afmeselhy@zu.edu.eg
}

Received 19 January 2012; Accepted 19 February 2012

Academic Editors: E. J. Nassar and A. O. Neto

Copyright (๑) 2012 A. Fathy et al. This is an open access article distributed under the Creative Commons Attribution License, which permits unrestricted use, distribution, and reproduction in any medium, provided the original work is properly cited.

A wide range of particulate metal matrix composites (PMMCs) of alumina and aluminum powders was formed using powder metallurgy techniques followed by extrusions at various extrusion ratios. The machining characteristics of the extruded PMMC were investigated. Results showed significant effects of weight fractions of reinforcement and extrusion ratios on tool wear and surface integrity of machined surface. The wear rate of cutting tool decreased rapidly with increasing the cutting parameters: cutting speed, feed, and depth of cut, however cutting speed is shown to be more effective. Sudden breakage of tool inserts occurred when the experiment started at high cutting speed. Wear rate has also decreased by decreasing volume fraction of reinforcement particles. Coating carbide tools have significantly improved the tool life. Coated tools showed 5\% decrease in flank wear size compared to uncoated tools. This was valid within tested range of weight fractions and extrusion ratios. The surface finish of machined surfaces deteriorated when coated carbide tools were used. However, surface finish did not change significantly when volume fractions or extrusion ratios were altered.

\section{Introduction}

Metal-matrix composites are used in variety of applications; space shuttle, commercial airliners, electronic substrates, bicycles, automobiles, golf clubs, and others. The vast majorities of these composites are aluminum matrix composites. The term metal matrix composite (MMC) covers various types of systems, and also a wide range of scales and microstructures. Common to them all is a metallic matrix and reinforcing constituents which are in most cases a ceramic. MMC types are commonly subdivided according to whether the reinforcement is in the form of (a) particles, which are at least approximately equiaxed, (b) short fibers (with or without a degree of alignment), or (c) long aligned fiber matrix and reinforcement. Compared to monolithic metals, MMCs have higher strength-to-density ratios, better fatigue resistance, better elevated temperature properties (such as high strength and low creep rate), lower coefficients of thermal expansion, high thermal conductivity, good damping characteristics, excellent wear properties and flexibility in design attributes. However, the utilization of the MMC in different industries is not as generalized as expected due to difficulties encountered with the machining of MMC materials. Cost-effective machining of aluminum MMC has not been proven. Studies of advancements in the materials show promise for machinability. The same holds true for tooling. New coatings for cutting tools show great promise for advancing the machinability of this class of material but have not been investigated in detail. In addition to the tool coatings, no optimization has been done on the presentation of the tool to the material. Effects of approach geometry (i.e., rake, lead) have not been incorporated into past studies nor have the geometry of the cutting edge of the insert $[1,2]$. The main problem when machining MMC is the extensive tools wear caused by the very hard and abrasive reinforcements. Several studies have been performed in order to examine the efficiency of different cutting materials, such as cemented carbide and diamond, in turning, milling, drilling, reaming, and threading of MMC materials [3, 4]. The test results showed the influences of the reinforcement material on tool wear and the surface integrity of MMC. In the subsurface zone, when the workpiece was machined with worn cutting tools, 
the reinforcements are fractured. Damage of the reinforcements, caused by the machining process, can lead to significant deterioration in the properties of the components [5]. The results obtained from the above-mentioned investigations indicate that there is a need for more thorough activities to study the particle behavior in the matrix when it contacts the cutting tool. Investigating the particle behavior during machining will help in maximization of tool life and minimization of tool wear. Minimization tool wear and improving surface finish will eventually reduce the cost of machining MMC materials. Since the reinforced particles are the main parameters for cutting tool wear and surface deterioration of machined surfaces. Further investigations are required to understand the cohesion, decohesion, and fracture of the particles in the parent matrix as result of machining and their relation to composite manufacturing parameters such as compacting pressure and various extrusion ratios.

\section{Experimental}

2.1. Fabrication of Composite. Metal matrix composites including various weight fractions of $\mathrm{Al}_{2} \mathrm{O}_{3}$ particles were produced by powder metallurgy techniques followed by extrusions. Commercial pure aluminum powder with the following chemical analysis: $99.4 \% \mathrm{Al}, 0.2 \% \mathrm{Si}, 0.15 \% \mathrm{Fe}, 0.1 \% \mathrm{Cu}$, $0.1 \% \mathrm{Mg}$, and $0.05 \% \mathrm{Mn}$ was used as the matrix material; while $\mathrm{Al}_{2} \mathrm{O}_{3}$ particle with an average size of $37 \mu \mathrm{m}$ were used as the reinforcement material. The composites were fabricated by mixing the $\mathrm{Al}$ alloy powder with $\mathrm{Al}_{2} \mathrm{O}_{3}$ powder in different weight fractions of $0,5,10$, and $15 \%$. The mixed powders were pressed in air as billets under a pressure of $420 \mathrm{MP}$ and sintered at $450^{\circ} \mathrm{C}$ for 6 hours. The billet dimensions were $40 \mathrm{~mm}$ diameter, $40 \mathrm{~mm}$ long, and about 90 pct of the theoretical density. Extrusion process was developed as secondary manufacturing process to consolidate $\left(\mathrm{Al}-\mathrm{Al}_{2} \mathrm{O}_{3}\right)$ composites obtained by pressing mixed powders. All of the compacted billets were extruded in an extrusion machine with various extrusion ratios $\left(r_{x}\right) ; 4.4,5.5,7.1$, and 9.5 at temperature $550^{\circ} \mathrm{C}$ to reach a fully consolidated state.

2.2. Cutting Conditions. The machining investigation was carried out using $\mathrm{Al}_{2} \mathrm{O}_{3}$ particle-reinforced aluminum alloy composites. The composites used in the present work were shaped in the form of cylinder of $12 \mathrm{~mm}$ outer diameter and height of $70 \mathrm{~mm}$ and were fabricated by extrusion process. For manufacturing of MMCs, 5, 10, and $15 \mathrm{wt} . \% \mathrm{Al}_{2} \mathrm{O}_{3}$ particles and extrusion ratios, 4.4, 5.5, 7.1, and 9.5 were used. An unreinforced alloy bar was also produced by an identical method. Machining tests were carried out to determine the tool wear or tool life and surface roughness under various cutting conditions when cutting three types of composites and their alloy matrix. The tests were conducted under different cutting conditions using a center lathe machine, which is 7.5 main motor horsepower, 16 spindle rotational speeds (ranges from 25 to $2000 \mathrm{rev} / \mathrm{min}$ ), and 15 longitudinal feeds rate (ranges from 0.04 to $1 \mathrm{~mm} / \mathrm{rev}$ ) used for turning the workpieces. The cutting speed was derived from the measured spindle speed and the diameter of the surface of
TABLE 1: Cutting tools used in the experiments.

\begin{tabular}{lcccc}
\hline Type of the tool & $\begin{array}{c}\text { Cutting tool } \\
\text { designation }\end{array}$ & $\begin{array}{c}\text { Cutting } \\
\text { fluids }\end{array}$ & $\begin{array}{c}\text { Cutting } \\
\text { speed } \\
(\mathrm{m} / \mathrm{min})\end{array}$ & $\begin{array}{c}\text { Depth of } \\
\text { cut }(\mathrm{mm})\end{array}$ \\
\hline Carbide tool & TPUN110408 116 & Dry & $54,67,80$ & 0.1 \\
Coating tool & TPUN110408 116 & Dry & $54,67,80$ & 0.1 \\
\hline
\end{tabular}

the workpiece. All tests were carried out without coolant at a depth of cut equal to $0.1 \mathrm{~mm}$ and feed rate of $0.03 \mathrm{~mm} / \mathrm{rev}$. The cutting conditions and tool geometry used in the experiment are listed in Table 1. The inserts were clamped mechanically in a rigid tool holder of CTOPR 1212F11 type. The work material to be machined is the $\mathrm{Al}_{2} \mathrm{O}_{3}$ reinforced MMCs. After each test, the worn cutting tool is measured with the optical tool microscope to determine the degree of flank wear and surface roughness of workpiece is measured.

\section{Results and Discussion}

3.1. Effect of Machining Parameters on Tool Wear and Surface Roughness. Most data from tool-life testing have been complied by carrying out simple lathe-turning tests, using tools with standard geometry, and measuring the width of the flank wear land. The results are sometimes presented using what is called Taylor equation $\left(V T^{n}=C\right)$ where $V$ cutting speed, $T$ cutting time corresponding to flank wear of $0.5 \mathrm{~mm}$, and $n$ and $C$ are parameters whose values depends on fee, depth of cut, and work material. These tests could also be used for the evaluation of the uncoated and coated cutting tool materials. Use of coated tools is expanding for improved tool life and higher cutting speeds. In machining MMC's, the evaluation of machining parameters such as cutting speed, feed, and depth of cut is very important in determine the tool life. However, the effect of cutting speed is greater than both feed and depth of cut. Therefore, in our work, the effect of cutting speed on various tools and work materials is carried out. Results of initial experiments showed that parameters of higher feed rate or larger depths of cut make the cutting tools suffer failure and workpiece surface deteriorates. Therefore, feed of $0.03 \mathrm{~mm} /$ revolution and depth of cut of $0.1 \mathrm{~mm}$ and same tool geometry were selected as the cutting condition and kept constant through all coming tests. Flank wear measurements as tool life criterion and surface finish as workpiece surface quality have been carried out and evaluated.

Figures 1 and 2 show the effect of cutting speed on tool flank wear for three cutting speeds, when machining the Al$10 \% \mathrm{Al}_{2} \mathrm{O}_{3}$ composite with extrusion ratio $=4.4$. Figure 1 shows the results when uncoated carbide cutting tool is used. If coated tool is used the results appear as in Figure 2. Tests were carried out under three various cutting speeds 54, 67 and $80 \mathrm{~m} / \mathrm{min}$. As cutting proceeds, the various wear mechanisms results in increasing levels of wear in cutting tool. Two regions can be identified in each curve. The first is the break-in period, in which sharp cutting edge wears rapidly at the beginning of its use. The break-in period is followed by the steady-state wear region, in which wear occurs at fairly uniform rate. In our figures, this region is figured as a linear 


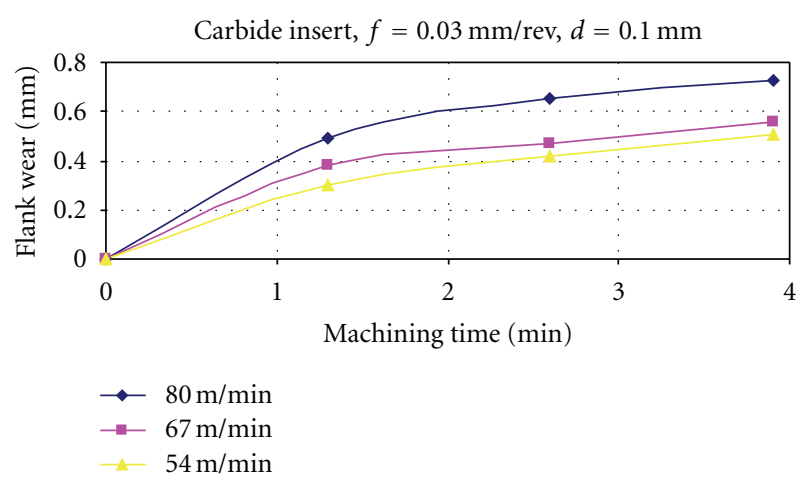

FIGURE 1: Flank-wear versus machining time at different cutting speeds using uncoated cutting tool $\left(\mathrm{Al}-10 \% \mathrm{Al}_{2} \mathrm{O}_{3}\right.$, Extrusion ratio $=4.4$ ).

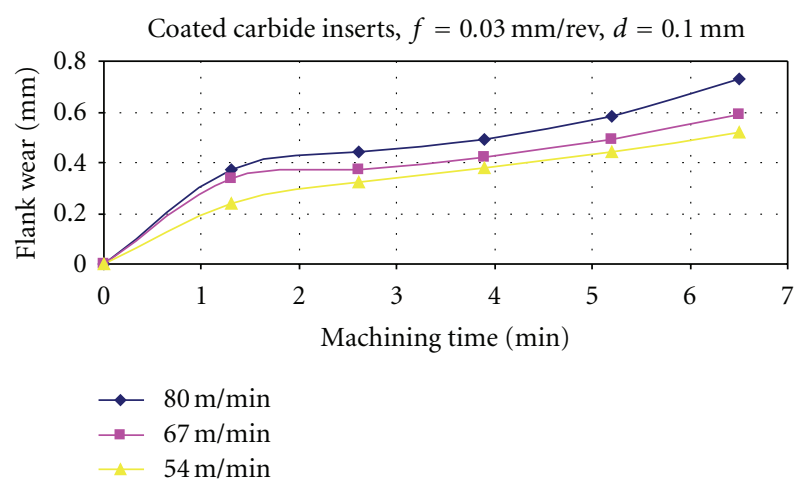

FIGURE 2: Flank-wear versus machining time at different cutting speeds using coated cutting tool. ( $\mathrm{Al}-10 \% \mathrm{Al}_{2} \mathrm{O}_{3}$, Extrusion ratio $=4.4$ ).

or nearly linear function of time. Finally, wear reaches a level at which wear accelerates. This marks the beginning of failure region. However, in production, it is often a disadvantage to use the tool until failure region occurs because of difficulty of tool resharpening and problem of work quality. The failure region was not seen in case of uncoated tool since time required to reach $0.5 \mathrm{~mm}$ (tool life criterion) was very short. Coated carbide tool has showed better performance in decreasing wear rate than that of the uncoated one. The time required to reach the same level of tool wear $(0.5 \mathrm{~mm})$ in coated tool was 4 minutes compared to 1.2 minutes in case of using uncoated tool (at cutting speed of $80 \mathrm{~m} / \mathrm{min}$ ). Coated tools can increase the tool life with more than 3.3 times of uncoated tools. Coatings are generally applied on cutting tools and inserts by chemical-vapor-deposition (CVD) technique. The coated tools with coating such as TiN or TiC have generally higher cutting-edge strength, lower friction, lower tendency to form built up edge, and good bonding to the substrate. Similar results were reported by Sahin and Sur [2], who concluded that tool life decreased with increasing cutting speeds and the major form of the tool wear was the mild abrasion and edge chipping on the flank face of the tool. Sahin et al. [1] showed that, in machining of various volume fractions of alumina particles, the flank wear is associated

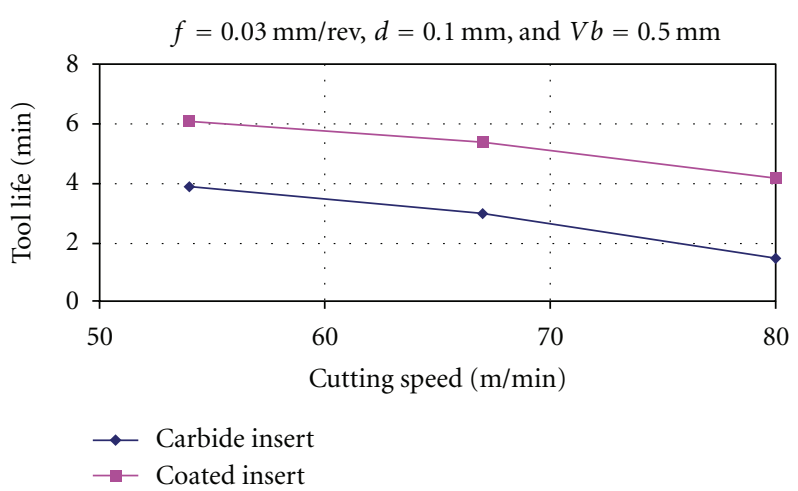

FIgUre 3: Tool life versus cutting speed for coated and uncoated cutting tools. $\left(\mathrm{Al}-10 \% \mathrm{Al}_{2} \mathrm{O}_{3}\right.$, Extrusion ratio $\left.=4.4\right)$.

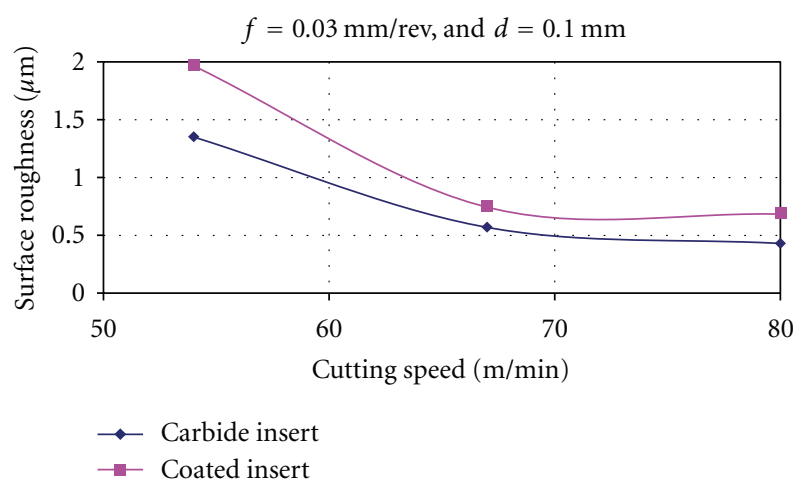

FIGURE 4: Surface roughness versus cutting speed for two different cutting tools. $\left(\mathrm{Al}-10 \% \mathrm{Al}_{2} \mathrm{O}_{3}\right.$, Extrusion ratio $=4.4$ ).

with BUE formation in addition to broken layer of coated material. They suggested that triple-layer coating was more resistant than double-layer coating based on tool life.

The effect of speed is also pronounced in Figures 3 and 4. As cutting speed is increased, wear rate increases, so the same level of wear is reached in less time. This is probably due to thermal softening of the workpiece as mentioned in [2]. The increase in temperature coupled with the high compressive stresses near the cutting edge could accelerate tool wear and lead to the shorter tool life at high speed. However, the extensive tool wear of MMC is caused by the very hard and abrasive reinforcements, in addition to high kinetic energy of the abrading alumina particles. If the tool life values extracted from the three wear rates curves shown in Figures 1 and 2 are plotted versus cutting speeds for both coated and uncoated cutting tools, the resulting relationship is shown in Figure 3. Basically, this figure indicates that higher cutting speeds result in shorter tool lives. It is also shown that coated carbide tool has higher tool lives values than uncoated ones within all tested speed range. It can also be seen that an appreciable reduction of tool lives at higher cutting speeds for all cutting tools. Other researchers have indicated that the wear resistant quality of coated tools is mainly because of their high resistance to adhesion and diffusion wear on the parts of the tool surface where seizure might occur [6]. However, abrasive wear due to hard particles of reinforcement composite in 
this work is believed to be most dominant type of wear due to the high kinetic energy of the abrading alumina particles. Surface roughness is generally described by arithmetic mean value $R_{a}$. Additionally, we may also use root mean square value $R_{q}$. Because of its simplicity, $R_{a}$ was adopted for this work as it is widely used in engineering practice. Acceptable limits for surface roughness are usually specified on technical drawing. Various surface, profilometers, are used to measure and record surface roughness.

Figure 4 shows surface roughness obtained using coated and uncoated cutting tools versus cutting speed. From this figure, it can be seen that increasing the cutting speed from 54 to $80 \mathrm{~m} / \mathrm{min}$ resulted in a remarkable improvement in the surface finish of the machined surface. Similar results were obtained by El-Gallab and Sklad [7] of improving surface roughness with an increase of cutting speed of metal matrix composite reinforced with SiC particles. However, the surface roughness values of the uncoated cutting tools were found to be lower than those of the coating cutting tools even though the uncoated tools showed higher values of flank wear. The reason is not quite clear because larger tool wear usually deteriorates the surface roughness and quality of the machined surfaces. This may be due to the high damage to the surface caused by discontinuous decohesion and fracture of alumina particles of using coated cutting tool. However, at higher cutting speeds, the differences in values of surface roughness, between using coated or uncoated cutting tools, become less significant. It is believed that built up edges, BUE, which are favored by low cutting speeds would be the main reason for higher surface roughness at low cutting speeds. As BUE is cyclically formed and breaks away, hard particles are then deposited on the newly created work surface, causing it to have higher surface roughness. This is in addition of broken alumina particles which make the surface even more deteriorated.

\subsection{Effect of Processing Parameters on Tool Wear and Surface} Roughness. In machining MMC's, the evaluation of processing parameters such as compacting pressure, temperature, weight fraction of reinforcement particles, and extrusion ratio is very important to determine the cutting tool lives. Only the weight fraction and extrusion ratio parameters are evaluated in this work. The other parameters such as compacting pressure and temperature were kept constant. As mentioned, the main problem when machining MMC is the extensive tool wear caused by the very hard and abrasive reinforcements. When the workpiece was machined with worn cutting tools, the reinforcements are fractured. Damage of the reinforcements, caused by the machining process, can lead to significant deterioration in the properties of the components [6]. The results obtained from the above-mentioned investigations indicate that there is a need for more thorough activities to study the reinforcement particles effects when they are in contact with the cutting tools. Investigating the particle behavior during machining will help in maximization of tool life and minimization of tool wear. Since the reinforced particles are the main parameters for cutting tool wear and surface deterioration of machined surfaces. Further

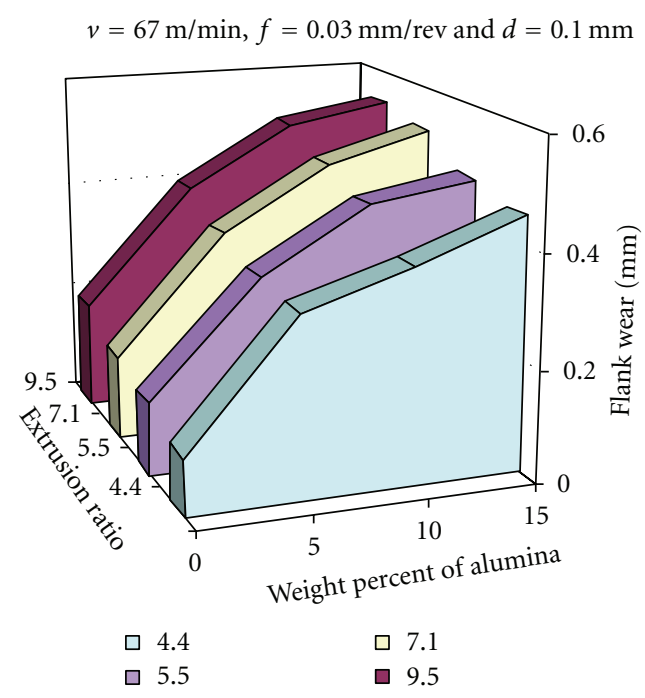

FIGURE 5: Histogram showing flank wear versus weight percent of alumina and extrusion ratio, using uncoated cutting tool. (Machining time $t=1.3 \mathrm{~min}$ ).

investigations are also required to understand the manufacturing parameters such as effect of altering the extrusion ratio on wear of cutting tools. Two types of tool materials, coated and uncoated, were selected for this work.

Figure 5 shows tool wear histogram relation, flank wear increases as increasing weight fraction of alumina and also increases when higher extrusion ratios were applied during extrusion operations. The effect of weight fraction is more pronounced in deteriorating surface quality compared to effect of altering the extrusion ratio. Figure 6 shows the same results when coated carbide cutting tool is used. Coating of cutting tool seemed to improve the surface finish. Since the pressure between workpiece and cutting tool is very high, much heat is generated and the cutting tool becomes softer and sometimes chemical diffusion occurs between the cutting tool and the chips.

Figures 7 and 8 show surface roughness histogram in relation to both weight fraction and extrusion ratio. Surface roughness of all composites has much lower values compared to commercial purity alloy alone ( $0 \%$ alumina). The improved surface finish may be due to the burnishing effect produced by the action of alumina particles trapped between flank tool face and machined surface of workpiece. Therefore, increasing weight fractions of reinforcement particle have reasonably decreased surface roughness. On other hand, surface roughness has slightly increased as extrusion ratio is increased. This is may be due to fineness effect of reinforcement particle as extrusion ratio is increased. The size of reinforcement particle has great effect on surface quality and strength of the composites as mentioned by Cho and Komvopoulos [5]. Previous work [8] reported that the size of reinforcement particles had much stronger effect on tool lives than that of population of reinforcement particles. Although coated-tool showed better tool wear resistance, the roughness obtained has showed higher values, when coated tools are used. It is believed that builtup edges, BUE, which are favored 


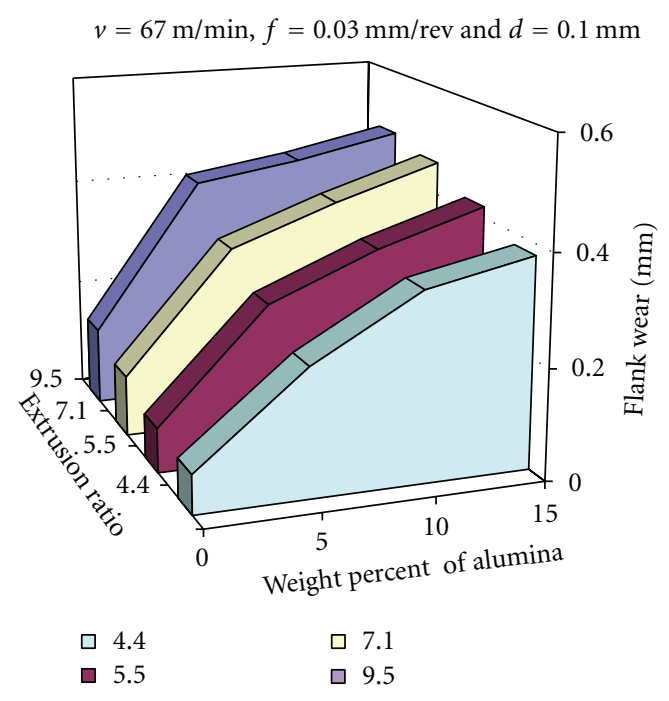

FIGURE 6: Histogram showing flank wear versus weight percent of alumina and extrusion ratio, using coated cutting tool. (Machining time $t=1.3 \mathrm{~min}$ ).

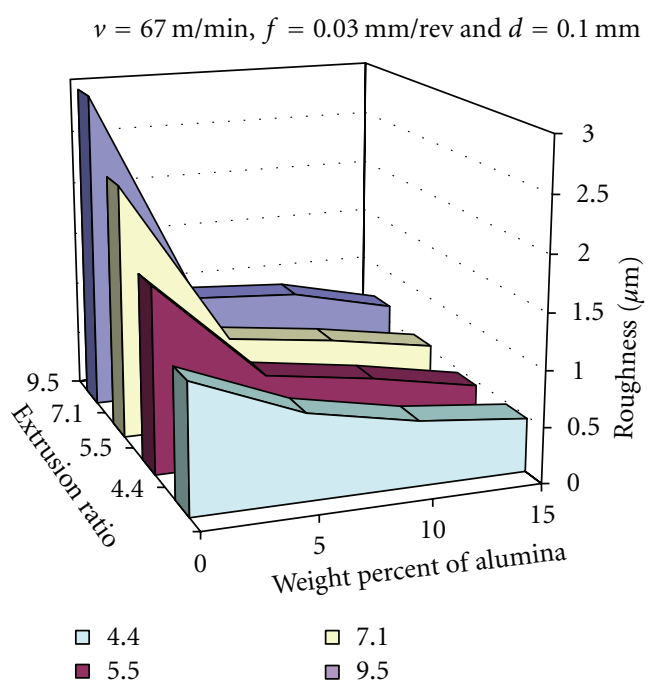

FIGURE 7: Histogram showing surface roughness versus weight percent of alumina and extrusion ratio, using uncoated cutting tool. (Machining time $t=1.3 \mathrm{~min}$ ).

by coated tool would be the main reason for higher surface roughness. This is because poor surface finish can be sometimes an indication of BUE formation. Similar works on machinability of MMC's with large volume fraction of reinforcement particle have shown poor machined surfaces when coated tools were used $[3,4,9]$. Previous works $[6,8]$ reported that the size of reinforcement particles had much stronger effect on tool lives than that of population of reinforcement particles. Looney et al. [3] found coated tools performed best in terms of flank wear but gave the poorest surface finish when machining composites of $\mathrm{SiC}$ as reinforcement particles. This is in consistent with the present study but of alumina as reinforcement particles was used instead of SiC.

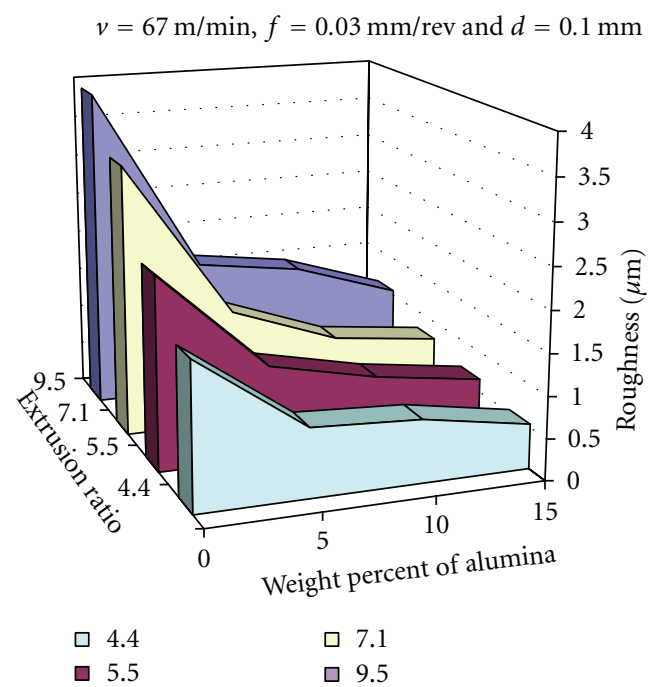

Figure 8: Histogram showing surface roughness versus weight percent of alumina and extrusion ratio, using coated cutting tool. (Machining time $t=1.3 \mathrm{~min}$ ).

\section{Conclusion}

In summary of machining tests to MMCs, using carbide inserts as cutting tools with and without coating, the following results were obtained during simple lathe turning tests.

(i) The wear rate increased rapidly with increasing the cutting parameters: cutting speed, feed and depth of cut, however cutting speed is shown to be more effective. Sudden breakage of tool inserts occurred when the experiment started at high cutting speed.

(ii) Coated tools can increase the tool life with more than 3.3 times of uncoated tools, at cutting speed of $80 \mathrm{~m} / \mathrm{min}$.

(iii) Wear rate of cutting tool has greatly influenced by changing the processing parameter such as weight fraction of reinforcement particles and extrusion ratios.

(iv) Wear rate of cutting tool increased as weight fraction of reinforcement particles was increased.

(v) Wear rate of cutting tool has also increased by increasing extrusion ratio from 4.4 to 9.5. However, the effect of weight fraction is more pronounced than extrusion ratio.

(vi) Surface roughness of reinforcement composites has much lower values compared to matrix commercial purity alloy alone.

(vii) Surface roughness of composites has slightly decreased as weight fractions of reinforcement particle are increased.

(viii) The uncoated tool produced better surface finish than coated cutting tools. However, coated tools performed better than uncoated tools in terms of flank wear. 


\section{References}

[1] Y. Sahin, M. Kok, and H. Celik, "Tool wear and surface roughness of $\mathrm{Al}_{2} \mathrm{O}_{3}$ particle-reinforced aluminium alloy composites," Journal of Materials Processing Technology, vol. 128, no. 1-3, pp. 280-291, 2002.

[2] Y. Sahin and G. Sur, "The effect of $\mathrm{Al}_{2} \mathrm{O}_{3}$, TiN and $\mathrm{Ti}(\mathrm{C}, \mathrm{N})$ based CVD coatings on tool wear in machining metal matrix composites," Surface and Coatings Technology, vol. 179, no. 2-3, pp. 349-355, 2004.

[3] L. A. Looney, J. M. Monaghan, P. O’Reilly, and D. M. R. Taplin, "The turning of an $\mathrm{Al} / \mathrm{SiC}$ metal-matrix composite," Journal of Materials Processing Tech., vol. 33, no. 4, pp. 453-468, 1992.

[4] J. T. Lin, D. Bhattacharyya, and C. Lane, "Machinability of a silicon carbide reinforced aluminium metal matrix composite," Wear, vol. 181-183, no. 2, pp. 883-888, 1995.

[5] S. S. Cho and K. Komvopoulos, "Wear mechanisms of multilayer coated cemented carbide cutting tools," Journal of Tribology, vol. 119, no. 1, pp. 8-17, 1997.

[6] Y. Sahin, "Preparation and some properties of SiC particle reinforced aluminium alloy composites," Materials and Design, vol. 24, no. 8, pp. 671-679, 2003.

[7] M. El-Gallab and M. Sklad, "Machining of $\mathrm{Al} / \mathrm{SiC}$ particulate metal-matrix composites Part I: tool performance," Journal of Materials Processing Technology, vol. 83, no. 1-3, pp. 151-158, 1998.

[8] K. H. W. Seah, X. Li, and K. S. Lee, "The effect of applying coolant on tool wear in metal machining," Journal of Materials Processing Tech., vol. 48, no. 1-4, pp. 495-501, 1995.

[9] I. Ciftci, M. Turker, and U. Seker, "Evaluation of tool wear when machining SiCp-reinforced Al-2014 alloy matrix composites," Materials and Design, vol. 25, no. 3, pp. 251-255, 2004. 

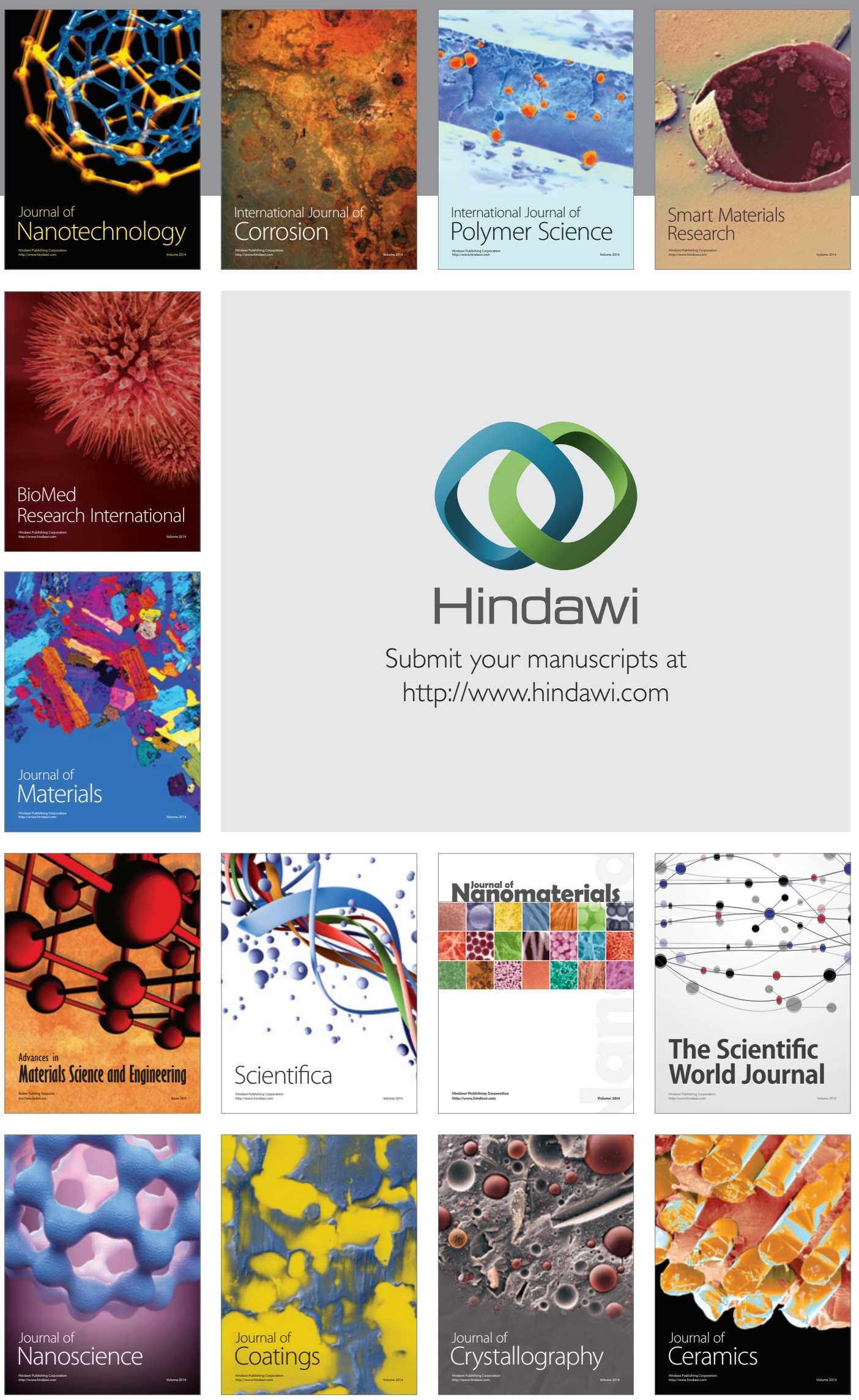

The Scientific World Journal

Submit your manuscripts at

http://www.hindawi.com

\section{World Journal}

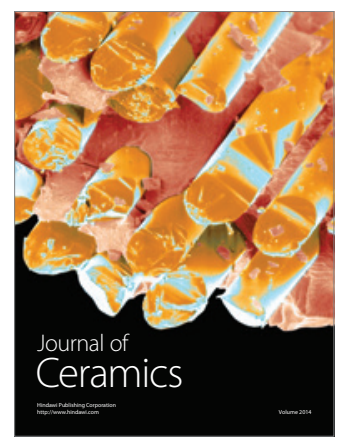

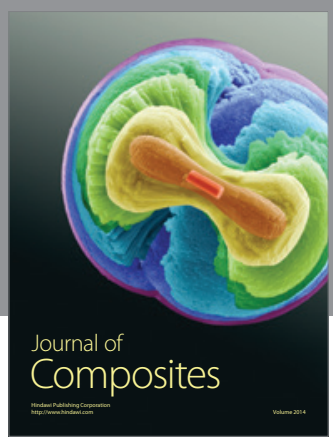
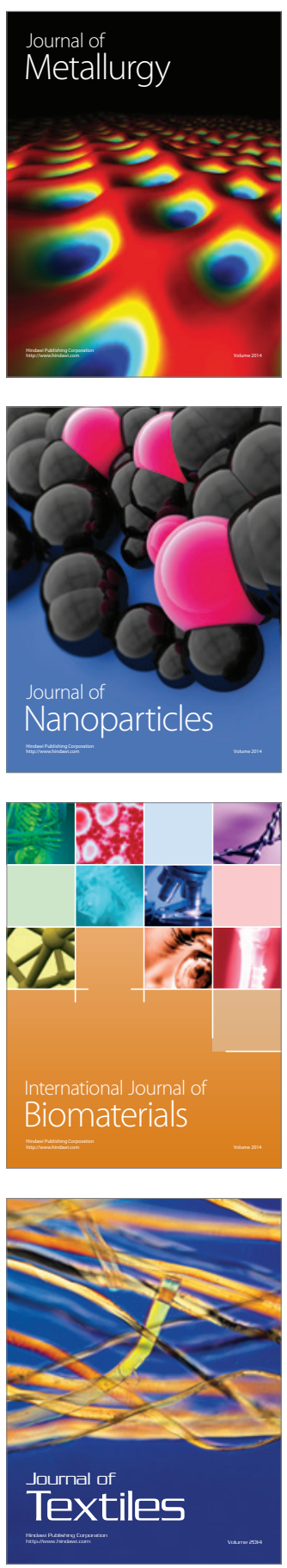